\title{
Mindvaults. Sociocultural Grounds for Pretending and Imaginining A book review
}

Author: Radu J. Bogdan

Publisher: The MIT Press

Release date: 2013

Number of pages: 256

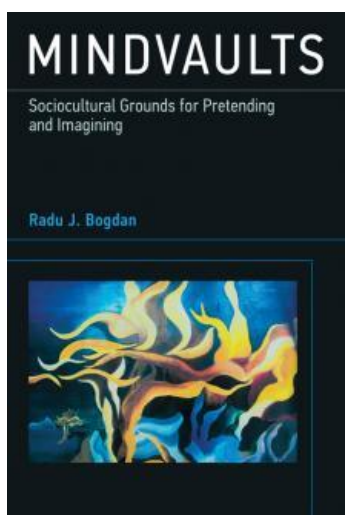

Paweł Gładziejewski

Department of Cognitive Science and Epistemology, Nicolaus Copernicus University, Torun, Poland pawel_g[]umk.pl

Received December 2013; accepted February 2014; published Summer 2014.

In his latest book, Radu J. Bogdan embarks on a quest as ambitious as one can imagine in the sciences of the mind: to explain the developmental (as well as evolutionary) path leading to human intellect, defined as "high-level mental faculties involved in reasoning, deliberate planning, thoughtful communication, reflective problem solving and decision making, art creation, technological innovation and scientific theorizing” (p. 218). Although not without some problems and shortcomings - and thus not quite successful at living up to its ambitious premise - this interesting work tackles its problems from an original theoretical perspective.

Bogdan's views are quite complex and in order to present his case the author introduces a number of novel, technical terms. Here, I only describe the general outline of his proposal. The book is composed of two parts. In Part I, ascetically titled "Questions", Bogdan is largely concerned with introducing a general theoretical/explanatory framework which he uses to achieve the main goal of the book. Bogdan argues that it is crucial for understating the origins of human-level thought to take a closer look at human-specific ontogeny during childhood. In line with evo-devo approach in evolutionary biology, 
Bogdan sees development as an important stage at which natural selection takes place. Indeed, from the perspective presented in the book, the human mind is armed by evolution with a number of cognitive adaptations for dealing with the socio-cultural environment that children are situated in. But this is not the whole story. Bogdan adds to this picture an "devo-evo" angle that “(...) tracks mental development as a sequence of ontogenetic niches, each with its own selection pressures, to which the young minds develop responses as ontogenetic adaptations and solutions" (pp. 20-21). When facing specific socio-cultural challenges of early ontogeny, children's evolutionarily older abilities assemble in a way that gives rise to mindvaulting, i.e. the capacity for mentally leaping over current perception, emotion and motivation, in order to mentally ponder non-actual, future, past, abstract or even impossible facts and scenarios. There are two forms of mindvaulting that arise at different stages during child's development: pretending and Imagining. It is the latter that Bogdan construes as an "engine of the intellect" ( $p$. xvii).

In Part II "Developmental Answers", Bogdan develops his account of the nature and sources of pretending and Imagining. To cut a long story short, the ability for pretending emerges before the fourth year of age as a way of dealing with the challenge of learning cultural roles and norms. It is based on a rudimentary context-bound form of "metamental rehearsals", i.e. processes of projecting possible social scenarios, in which mental states of oneself or others are taken into account. Performing these metamental rehearsals requires the child to antecedently and independently acquire an intuitive psychology, at least in its developmentally early form, dubbed by Bogdan "naive psychology". After the age of four, the child acquires a set of new executive and metaconigitive abilities - including a more sophisticated form of intuitive psychology ("commonsense psychology") - that give rise to Imagining, the second form of mindvaulting. Imagining arises as an answer to sociopolitical challenges that the child is faced with after the age of four. It is subserved by the capacity to perform more sophisticated and elaborate metamental rehearsals. When performing those metamental rehearsals, the child acquires the ability to treat mental states as tools. That is, within the projection, the child can manipulate mental states to eventuate states of affairs occurrence of which could potentially help it to advance its position in a web of social interdependencies and relations. Lastly, through "competence transfer", Imagining, the ability to perform complex off-line thinking about thinking, is disseminated to other than social/psychological domains, thus giving rise to intellect.

As I have mentioned at the outset, this book is very ambitious in its attempt to explain human intellect. What I find particularly valuable and interesting about Bogdan's undertaking is the author's theoretical approach to how the book's main problems should be handled. According to Bogdan, we cannot understand how human-level cognition emerges unless we concentrate on how human minds are both evolutionarily adapted to and ontogenetically 
dependent on ongoing interactions with our socio-cultural environment. This approach underscores the explanatory role of children's ontogeny and the way it unfolds in close connection with the socio-cultural environment, but at the same time avoids (what I take to be) the pitfall of attributing to the social environment a constitutive, and not just enabling, function in shaping cognition (see Hershbach 2012). Although inspired by an evolutionary outlook on the origins of cognition, Bogdan's perspective also contrasts with the modularist-nativist perspective characteristic of traditional evolutionary psychology and fits nicely with proposals which, although evolution-friendly, assume that culture and cultural learning play a fundamental role in shaping human minds (see e.g. Herrmann, Call, et. al. 2007; Sterelny 2003).

Nonetheless, Mindvaults... is surely not without some problems. Some of the ideas presented in the book are not fully conceptualized or argued for with a sufficient level of clarity and detail. For example, Bogdan postulates that human capacity for reflexive, controlled and domain-independent thinking (intellect) is preceded and enabled by metamental-rehearsal-based thinking about the social/psychological domain. The author discusses numerous similarities and parallels between both processes. Still, the exact path from metamental rehearsals to domain-independent intellect - with the latter expressing itself, among others, in the ability to create art and think about mathematical problems or counterfactual causal relationships between middle-sized objects - is postulated rather than explained or discussed in detail that could and should be expected. Additionally, to see how this idea of Bogdan's may in fact be somewhat problematic, note that to explain how Imagination emerges during ontogeny, he assumes that a number of quite sophisticated executive and metacognitive prerequisite capacities are in place at certain stages of childhood. But is seems that sometimes he may be assuming too much, presupposing at least some of the very capacities he sets out to explain. For example, the capacity for Imagination stems from metamental rehearsals that are used in strategizing and which require the ability to use commonsense psychology. But it has been quite persuasively argued by some authors - both from the theory-theory and simulation-theory camps - that the ability to interpret others in mental terms requires the capacity for suppositional thinking about domains other than psychological (see Carruthers 1996; Heal 2003; Goldman 2006). To predict someone's decision with regard to some non-psychological domain $x$, the child needs not only to represent someone's mental states, but also to have the ability to make counterfactual inferences about the domain itself. If this is true, then metamental rehearsals require at least some degree of domain-independent suppositional thinking rather than subserve it.

There are other problems with Mindvaults... as well. Bogdan at least once misqoutes his sources. He attributes (pp. 88-89) to Alvin Goldman a "rich" version of simulation theory of mindreading, one according to which simulation used in mindreading is a reflexive and voluntarily controlled process. 
This is wrong, since Goldman (2006) also postulates the existence of an automatic simulation process - realized at the neural level by mirror systems that underlies a so-called low-level mindreading. Furthermore, it seems to me that the book could make use of a more systematic and detailed review of empirical literature that, according to the author, supports his main theses. Instead, Bogdan mostly glosses over empirical matters and the reader is expected to be already familiar with relevant results in developmental psychology or primatology. Lastly, it needs to be mentioned that this book is not exactly an easy read. As I have mentioned before - and as may be seen from my brief review of the book's contents - to present his case, Bogdan introduces a number of technical and idiosyncratic terms and metaphors; there are so many of these that the main part of book is followed by a short glossary (helpful, albeit not quite complete).

Despite these shortcomings, I think that Mindvaults... is worth the read, especially for researchers interested in explanations of cognition that are both evolutionarily and developmentally-oriented. Although not wholly persuasive and occasionally lacking in clarity and detail, the book represents a refreshing and interesting attempt at explaining human-specific intellectual abilities.

\section{References}

Carruthers, P. 1996. Simulation and self-knowledge: a defence of theory-theory. P. Carruthers, P.K. Smith, eds. Theories of Theories of Mind: 22-38. Cambridge: Cambridge University Press.

Goldman, A. 2006. Simulating Minds: The Philosophy, Psychology and Neuroscience of Mindreading. Oxford: Oxford University Press.

Heal, J. 2003. Mind, Reason, and Imagination: Selected Essays in Philosophy of Mind and Language. Cambridge: Cambridge University Press.

Herrman, E., Call, J., Hernàndez-Lloreda, M.V., Hare, B., Tomasello, M. 2007. Humans have evolved specialized skills of social cognition: the cultural intelligence hypothesis. Science, 317: 1360-1366.

Herschbach, M. 2012. On the role of social interaction in social cognition: a mechanistic alternative to enactivism. Phenomenology and the Cognitive Sciences, 11: 467-486.

Sterelny, K. 2003. Thought in a Hostile World: The Evolution of Human Cognition. Oxford: Blackwell. 